\title{
Performance Evaluation and Modification of an Existing Rice Destoner
}

\author{
Mohammed Gana Yisa, Adeshina Fadeyibi ${ }^{\ddagger}$, Kamil Kayode Katibi, O. C. Ucheoma \\ Department of Food, Agricultural and Biological Engineering, College of Engineering and Technology, Kwara State \\ University, Malete, P. M. B. 1530, Ilorin, Kwara State, Nigeria. \\ (mgyisa@gmail.com, adeshina.fadeyibi@kwasu.edu.ng, kamil.katibi@kwasu.edu.ng, gana.yisa@kwasu.edu.ng) \\ ¥Corresponding Author; Dr. Adeshina Fadeyibi, P. M. B. 1530, Ilorin, Kwara State, Nigeria, Tel: +2347034867681 , \\ Fax: +234 7034867681 ,adeshina.fadeyibi@kwasu.edu.ng
}

Received: 07.07.2017 Accepted: 22.09.2017

\begin{abstract}
Destoning is a processing technique for removing stones and broken grains from a batch of milled rice. This research was carried out to modify an existing rice destoner for the purpose of increasing its capacity and efficiency. Modification introduced addressed challenges associated with the existing machine, such as low stone removal efficiency and low air flow channel, which affects the aerodynamic lifting of the rice grains. Performance was evaluated for $3 \mathrm{~kg}$ of locally milled rice samples based on the design capacity of the machine, cleaning efficiency and degree of grain flow. The result showed that the design capacity $(1.8 \mathrm{~kg} / \mathrm{h})$ of the modified destoner was higher than that of the existing $(0.86 \mathrm{~kg} / \mathrm{h})$. Also, the modified machine has $40.8 \%$ destoning efficiency which is higher than that of existing machine $(2.58 \%)$.
\end{abstract}

Keywords Cleaning efficiency, Design, Material flow efficiency, Rice destoner, Rice.

\section{Introduction}

Domestic processing of rice for local consumption and export is nowadays a serious business in Nigeria [1,2]. This is probably because of the renewed interest by government for the country to be self-sufficient in terms of food production rather than depending on importation of major agricultural commodities. Rice production is generally carried out by the local farmers who have little or no idea of modern technology as currently applied in agriculture [3]. Research efforts has shown that production and processing technologies have not been able to meet the increasing demand for rice [4]. This is true despite the huge production potential of the commodity in Nigeria judging from the vast arable and fertile land available for cultivation. Therefore, instead of spending billions of naira on importation, the commodity can be produced, processed and bagged for local consumption and export [5]. It is usually difficult to actualize this mandate without proper agricultural mechanization. Of course rice processing is not new to cultivators, but this is done locally and in the process impurities including stones introduced. The presence of impurities inadvertently makes marketing tedious as consumers prefer clean quality rice product.

Prior to the conception of rice destoner, farmers make use of the traditional or manual method to separate impurities from rice. The manual method include handpicking which allows separation of stones from rice. But this is time consuming, tedious and contaminants such as stones, sticks, chaff and sand are not completely removed [6]. Another method is floatation which allows separation based on differences in density when a batch of unclean rice product is allowed to settle in bath of water. The heavier materials, which are stones, quickly settle to the bottom, and the clean rice at the top are carefully scooped. This, however, requires sufficient drying after separation and there is possibility of mold or fungi growth in storage when not properly dried [7]. Moreover, during rice processing, impurities may be purposely, accidentally, inevitably, or incidentally added. The level of impurities in rice, which are generally defined in relative terms, depends on the method of cleaning or separation used [8]. Standards have been established by various organizations that attempt to define the permitted levels of impurities in a manufactured product. Strictly speaking, the level of purity of the material can only be 
stated as being more or less pure than some other material. Some of the factors that make the locally produced rice less acceptable are impurities like stones, dust and chaff, and these get into rice as a result of poor methods of harvesting and drying used by the farmers. As much as possible, therefore, the level of impurity in processed rice should be reduced so as to ensure quality of the final product.

Many researchers have developed machines for use in removing stones and other impurities from processed rice, so as to meet the demand for clean product by consumers [9$12,8]$. This has resulted to several breakthroughs in the innovation and method of separating impurities from rice. For instance, Adejuyigbe and Bolaji [12] developed a rice destoning machine using a vibrating sieve and reported a high destoning efficiency. Okunola et al. [8] developed a cereal cleaner which is particularly adoptable for use in cleaning impurities in processed rice. Henderson and Perry [9] designed a separator based on gravity and floating. The disadvantages of using separator however in rice cleaning are that sufficient drying is required after separation and there is possibility of mold or fungi growth in storage [7]. However, the technical requirements of the designs described are quite cumbersome and difficult to localize [6, 11-13]. This is probably the reason rice processing is still a major challenge in some instances despite the level of research achieved. Therefore, attempt to readdress the design concept and improve performance cannot be overlooked. At the moment, there is no reported attempt to modify the existing rice destoners in order to achieve this. Thus, the objective of this research was to evaluate the performance of an existing rice destoner and modify the machine in terms of destoning efficiency.

\section{Materials and Methods}

\subsection{Materials}

The materials used in the design of the modified rice destoner are local rice weighing balance, stop watch, electric motor and air flow meter. Mild steel material was used for the fabrication of the machine.

\subsection{Performance and challenges of existing rice destoner}

An existing rice destoner designed and fabricated by Nwoba [14] shown in Fig. 1 was evaluated for its performance. Three samples of gwarri rice variety $(3 \mathrm{~kg}$ each and containing $0.5 \mathrm{~kg}$ of stones) were used to evaluate the performance of the destoning machine. As the machine operates, it vibrates the sieves and the grain mixture flows from the hopper through the vibrating sieves to the destoning section. In principle, the macine operates based on differences in terminal velocities of stone, rice and other impurities through aspiration. The machine was equipped with a blower (blast fan) which supplied air stream across the flowing grains. This caused the mixture of grains and stones to move at different velocities in different projectile directions. The machine was operated with a single phase $3 \mathrm{hp}(2.250 \mathrm{~kW}, 1440 \mathrm{rpm})$ electric motor and loaded. Cleaning efficiency of $73 \%, 2.58 \%$ and $93 \%$ were reported for chaff, stone and material flow, respectively. However, the stone cleaning efficiency of this design was extremely low, thereby causing both stones and chaffs to drop at the inlet of the flow channel. There were problems with the blower and obstruction caused by stone-chaffs mixtures in the stone tank. It was also reported that the airflow channel was not high enough to lift rice.

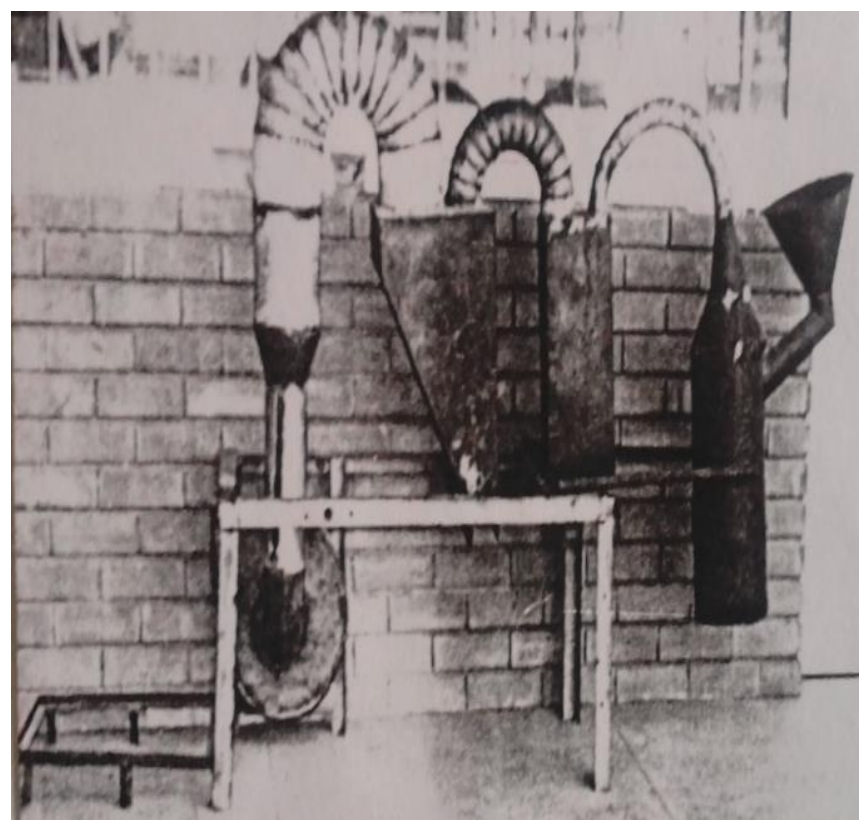

Fig. 1. Rice destoner constructed by Nwoba [14].

\subsection{Design Concept for Modification}

One of the problems associated with the rice destoner developed by Nwoba [14] was low stone cleaning efficiency. This problem appeared because the design did not take care of some factors influencing the performance of the various components of the cleaning systems, which are engineering properties of rice including physical, mechanical and aerodynamic properties. In this modification therefore, the aerodynamic characteristics of the rice grains, including density, terminal velocity, forces acting on the rice particles and the aerodynamic drag force, were determined according to the procedures described in Razavi et al. [15] and Tabatabee-far [16]. Physical characteristics, including shape and size, were determined by the method described by Fadeyibi et al. [7]. Mechanical characteristics were the angle of repose of rice grains determined by the method described by Nwithiga and Moriasi [17].

\subsubsection{Design Analysis}

The design analysis was carried out with a view to evaluating the design parameters for selection of the machine parts, so as to minimize failure during the required working life of the machine.

\section{Determination of hopper volume}

Hopper was made of galvanized and iron sheet so as to prevent rusting and sagging due to the weight of rice grains 
introduced. To achieve this requirement, a better hopper rigidity was analyzed and ensured as shown in Fig. 2. Thus, the volume of the hopper was calculated using the expression in Eq. (1).

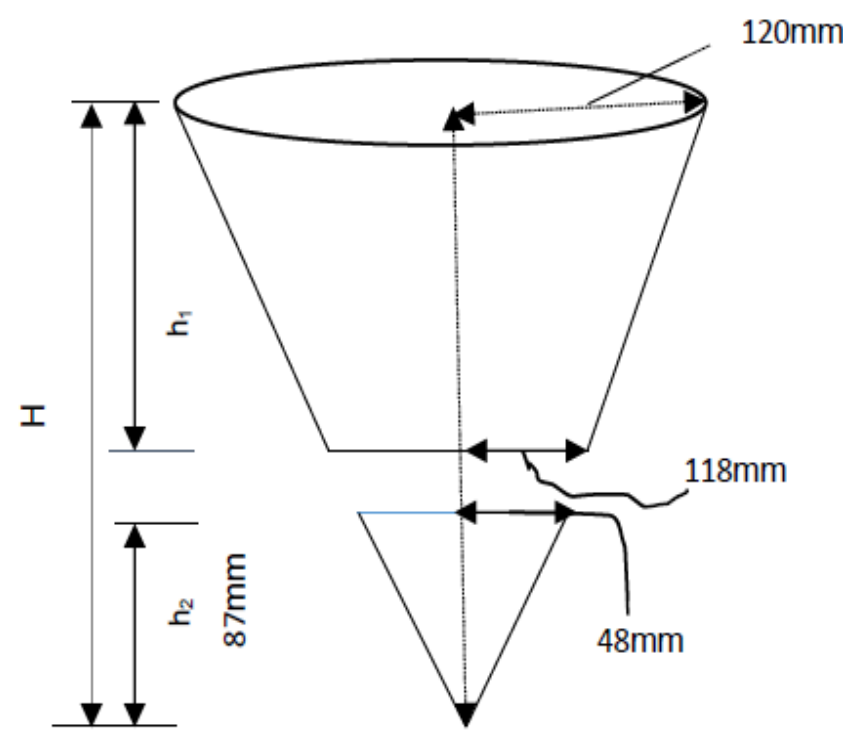

Fig. 2: Hopper analysis.

$V=\frac{1}{a} \pi r^{2}\left(H-h_{2}\right)$

but,

$$
H=h_{1}+h_{2} \text { or } h_{1}=H-h_{2}
$$

By similar triangles the solution is:

$$
\frac{R}{r_{2}}=\frac{h_{1}}{h_{2}}
$$

where, $\mathrm{R}=$ base radius of the hopper, $r_{2}=$ truncated radius of the hopper, $h_{1}=$ hopper vertical height, $h_{2}=$ truncated vertical height.

Thus,

$$
h_{1}=\frac{R}{r_{2}} \times h_{2}=\frac{118 \times 87}{48}=214 \mathrm{~mm}
$$

Then the volume of the hopper was:

$$
V=1 / 3 \pi(120)^{2} \times 214=3227462 \mathrm{~mm}^{3}
$$

Therefore, a total height $H=h_{1}+h_{2}=310 \mathrm{~mm}$ and the effective height of $220 \mathrm{~mm}$ with a volume of $3227462 \mathrm{~mm}^{3}$ were used as hopper specification of the rice destoner.

\section{Determination of volume of grain channel}

Grain channel are perforations where the whole rice grains pass through without allowing impurities. In this design, the grain channel was made of galvanized iron because it is less vulnerable to rusting and available in comparison to plain mild steel. The rusting effect of mild steel was also considered after which galvanized steel was chosen to avoid contamination due to rusting as the machine lasts in use. The grain channel is cuboidal in shape, as shown in Fig. 3. Assume a length of $40 \mathrm{~mm}$, width of $36 \mathrm{~mm}$ and height of $40 \mathrm{~mm}$, then the volume of the grain channel was calculated using Eq. (2).

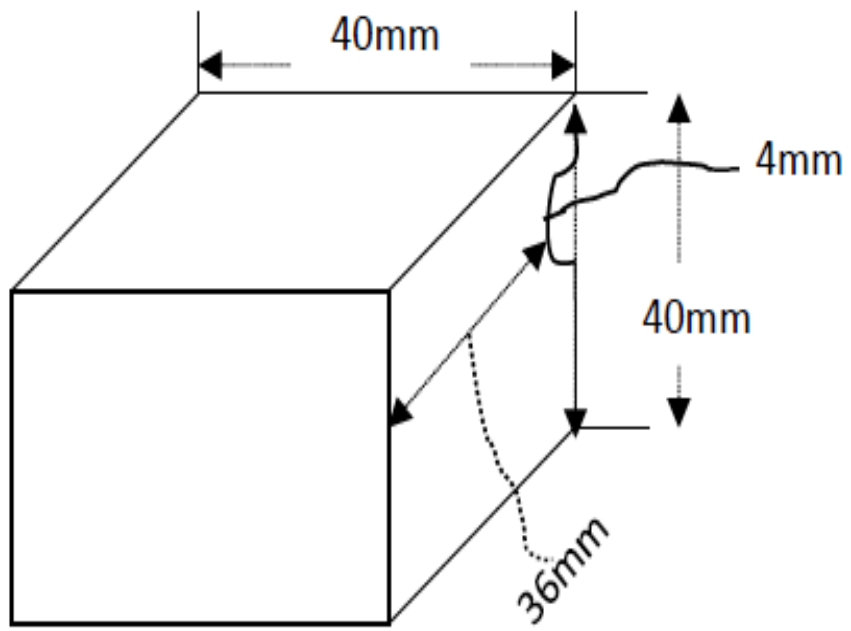

Fig. 3. Typical sketch of grain channel.

$V_{g e}=l w h$

where, $V_{g e}=$ volume of grain channel $\left(\mathrm{mm}^{3}\right), l=$ length of channel $(\mathrm{mm}), w=$ width of channel $(\mathrm{mm}), h=$ height of channel (mm).

$$
V_{g e}=40 \times 36 \times 40=57600 \mathrm{~mm}^{3}
$$

\section{Determination of blower discharge capacity}

Blower was selected based on the volume of air required and its resistance in the system as shown in Fig. 4. Density of air at normal atmospheric pressure and temperature was used to determine air speed by the blower using Eq. (3).

$Q=Q_{1} \sqrt{\frac{\rho_{25 \pi}}{\rho_{s t}}}$

where, $Q_{1}=$ discharge air speed by the blower $\left(\mathrm{m}^{3}\right), p_{25^{7} \mathrm{C}}=$ air density at $25^{\circ} \mathrm{C}\left(1.18 \mathrm{~kg} / \mathrm{m}^{3}\right), \rho_{s t}=$ air density at standard outdoor conditions $\left(1.12 \mathrm{~kg} / \mathrm{m}^{3}\right.$ for $40^{\circ} \mathrm{C}$ as obtained from specification of air conditioning and refrigeration table), $\mathrm{Q}=$ real discharge capacity of fan $\left(5,560 \mathrm{ft}^{3} / \mathrm{min}\right)$.

$$
Q=5560 \sqrt{\frac{1.18}{1.12}}
$$

$$
Q=5707 \mathrm{ft}^{3} / \mathrm{min}=2.69 \mathrm{~m}^{3} / \mathrm{s} \text { of air. }
$$




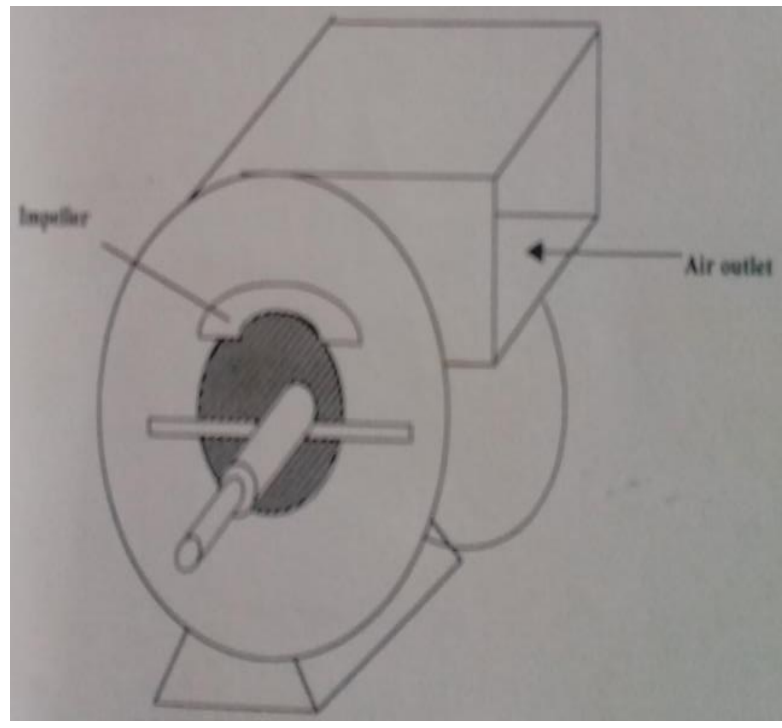

Fig. 4. A centrifugal fan.

Also, the power required to operate the centrifugal fan based on the amount of air stream flow rate $\left(2.69 \mathrm{~m}^{3} / \mathrm{s}\right)$ was $1.54 \mathrm{HP}$ (obtained from specification of air conditioning and refrigeration table). Thus, a $2 \mathrm{HP}$ electric motor was selected to provide the power required by the fan and to take care of the power loss in the system.

\section{Determination of angular velocity of sieves}

The frequency of vibration of the sieves was determined based on whirling speed of the shaft, blades and pulley from Dunkerly's formula expressed in Equation (4). Also, the centripetal velocity was considered as the sieves rotate with the aid of blades attached to the fan shaft.

$\bar{\omega}_{s}=\left(\frac{\pi^{2}}{\eta^{2} D}\right) \sqrt{\frac{E I}{m}}$

but since $m=\rho v$, then

$\bar{\omega}_{s}=\left(\frac{\pi^{2}}{\left.l^{2}\right)}\right) \sqrt{\frac{E l}{\rho \nu}}$

where, $l=$ length of shaft $(0.56 \mathrm{~m}), \mathrm{I}=$ moment of inertia, $\mathrm{m}$ $=$ mass of shaft $(\mathrm{kg}), \mathrm{v}=$ volume of shaft $\left(\mathrm{m}^{3}\right), \rho=7,800$ $\mathrm{kg} / \mathrm{m}^{3}, \mathrm{E}=$ Elastic modulus $\left(2 \times 10^{6} \mathrm{~N} / \mathrm{m}^{2}\right), \bar{\omega}_{\Omega}=$ whirling speed $(\mathrm{rad} / \mathrm{s})$.

$$
\begin{gathered}
I=\pi \times \frac{(0.03 a 7)^{2}}{64}=5.58 \mathrm{~m}^{4} \\
v=\pi \frac{(0.02 a 7)^{2}}{4} \times 0.56=0.0005 \mathrm{~m}^{3} \\
m=7800 \times 0.0005 \\
\therefore m=3.90 \mathrm{~kg}
\end{gathered}
$$

$$
\begin{array}{r}
\bar{\omega}_{s}=\left(\frac{\pi^{2}}{0.56^{2}}\right) \sqrt{\frac{2 \times 10^{6} \times 5.58}{3.90}} \\
\bar{\omega}_{g}=31.5 \times 0.18=5.68 \mathrm{rad} / \mathrm{s}
\end{array}
$$

Thus, the angular velocity of sieves was $5.68 \mathrm{rad} / \mathrm{s}$

\section{Determination of column maximum deflection}

The maximum column deflection of the shaft of the modified destoner was computed from Eq. (5).

$Y_{\max }=5 W^{4} / 384 E I_{x x}$

where, $\mathrm{W}=$ load per unit length $(\mathrm{N} / \mathrm{m}) ; \mathrm{L}=$ length of column $(\mathrm{m}) ; \mathrm{E}=$ modulus of elasticity $\left(\mathrm{kg} / \mathrm{m}^{2}\right) ; I_{x x}=$ moment of inertia in the $\mathrm{x}$ - direction $\left(\mathrm{m}^{4}\right) ; \mathrm{Y}_{\max }=$ vertical maximum deflection (m).

\section{Determination of safe load capacity}

The load required to safely operate the machine without hindrance or failure was computed using Euler's equation for permissibility load as expressed in Equation (6).

$P_{e}=\pi^{2} \cdot E \cdot I_{x x} / L_{e}$

where, $P_{c}=$ crippling load $\mathrm{E}=$ modulus of elasticity; $I_{x x}=$ moment of inertia in the $\mathrm{x}$ - direction; $L_{e}=$ effective length.

\section{Determination of strain energy}

The strain energy from the column deflection on the rice destoner was computed using Eq. (7).

$U=\left(P_{\theta}^{2} / 2 E\right) \times V$

where, $P_{e}=$ elastic stress constant; $\mathrm{V}=$ volume of material; $\mathrm{E}$ $=$ modulus of elasticity; $U=$ strain energy.

\section{Determination of pressure distribution in the system}

In order to determine the pressure distribution in the system the discharge velocity, continuity velocity and the density of air at room temperature, $24^{\circ} \mathrm{C}$ were considered as influencing factors. The pressure distribution in the system was therefore computed from Eq. (8).

$\frac{p}{\rho_{25} v}+\frac{U_{2}}{2 g}=\frac{P_{1}}{\rho_{25} v}+\frac{V^{2}}{2 g}$

where, $P_{1}=$ continuity pressure; $P_{24^{\circ} \mathrm{C}}=$ density of air at $24^{\circ} \mathrm{C}$; $U_{2}=$ discharge velocity/fan velocity, $\mathrm{g}=$ acceleration due to gravity $\left(9.81 \mathrm{~m} / \mathrm{s}^{2}\right) ; \mathrm{V}=$ velocity due to continuity $(\mathrm{m} / \mathrm{s})$.

\section{Determination of fan shaft diameter}

The shaft diameter was determined using the expression in Eq. (9). According to Khurmi and Gupta [18], the diameter of a solid shaft with little or no axial load can be determined using: 
$d^{a}=\frac{16}{\pi s_{x}}\left[\left(k_{b} m_{b}\right)^{2}+\left(k_{t} m_{t}\right)^{2}\right]^{1 / 2}$

where, $k_{b}=$ combined shock and fatigue factor applied for bending moment $=1.5, k_{t}=$ combined shock and fatigue factor $=1 ; m_{b}=$ maximum bending moment, $m_{\mathrm{t}}=$ maximum torsional moment; $S_{s}=$ allowable stress= $40 \mathrm{MN} / \mathrm{m}^{2}$ for shaft with keyway (machine design $\mathrm{S}$ series).

\section{Bearing selection}

Bearing selection was based on load requirement, speed of shaft, space limitation and desire for precise shaft positioning. Eq. (10) was used to compute the bearing rated life. For agricultural equipment, the design life $\mathrm{L}_{10}$ is between 3000-6000 [18]. This specification was used as guide for the bearing selection.

$L_{10}=\left(\frac{C}{p}\right)^{k} \times \frac{10^{6}}{60 \mathrm{n}}$

where, $L_{10}=$ rated life, revolution; $\mathrm{C}=$ basic load rating $=$ 1525.44 N; P= equivalent radial load, $\mathrm{K}=$ constant, 3 for single groove type, $\mathrm{n}=2000 \mathrm{rpm}$ (obtained from table of materials properties) [18].

However,

$P=X V f_{r}+Y f_{a}$

where, $\mathrm{X}=$ radial load factor $(0.56)$ from table of materials properties, $\mathrm{V}=$ radial factor $(1), f_{F}=\operatorname{radial}$ load $(120 \mathrm{~N})$, $f_{\alpha}=0.7 f_{r}=0.7 \times 120=84 \mathrm{~N}$.

\subsubsection{Drawing of modified rice destoner}

Isomeric and orthographic projections of the modified rice destoner are shown in Fig. 5 and Fig. 6, respectively.

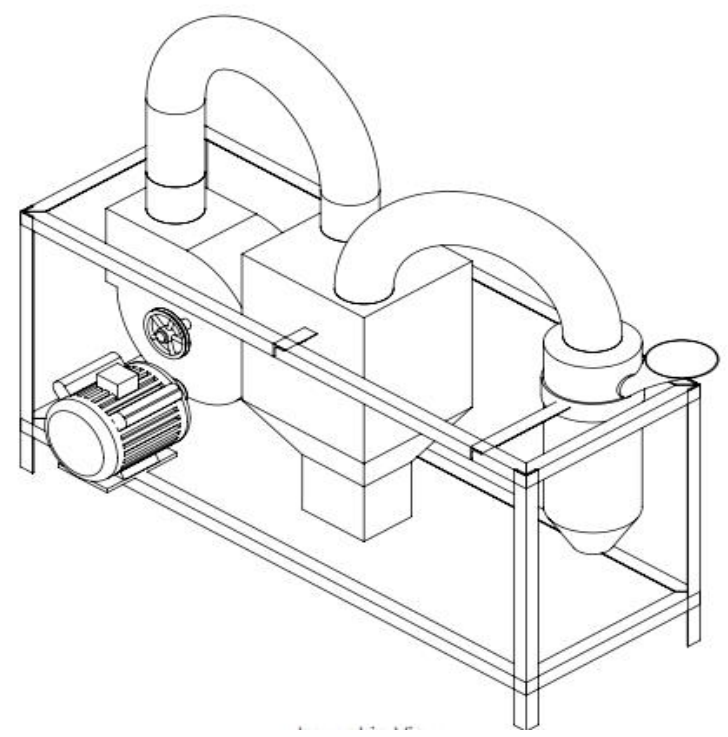

Fig. 5. Isometric view of rice destoner.

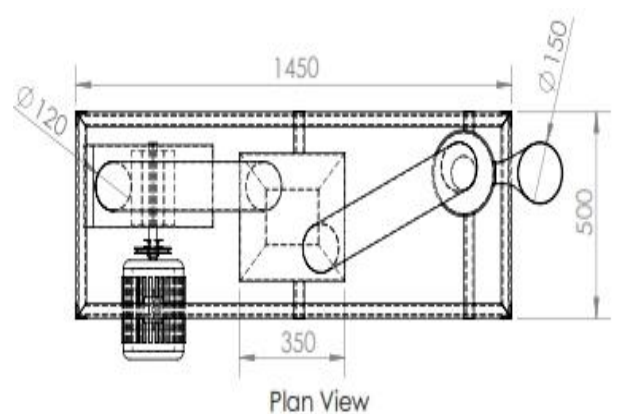

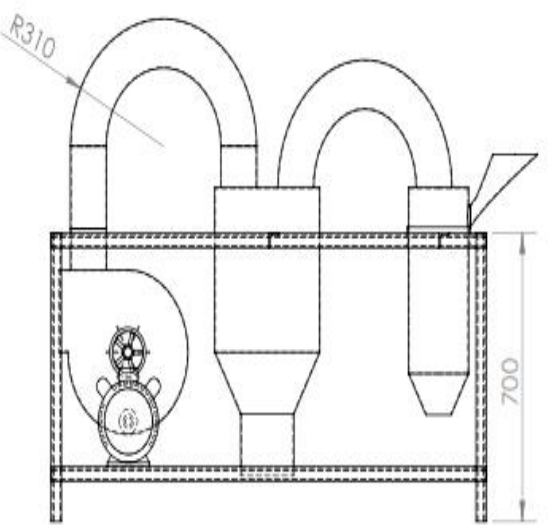

Front View

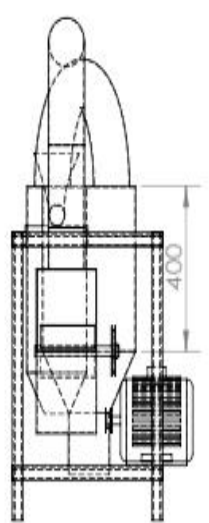

Side View
Fig. 6. Orthographic projection of rice destoner.

\subsection{Principle of operation of modified rice destoner}

The rice destoning machine was designed to achieve complete separation of stone from rice. The admixture (mixture of rice and stone) was fed through the hopper and into the vibrating sieve which allows stones smaller than the rice to pass through. Any stone that is larger than the diameter of the sieve size $(\geq 2 \mathrm{~mm})$ will fall along with the rice onto the vibrating sieve. The vibratory sieve transfers the stones in the opposite direction of the flow of clean rice so that the cleaned rice will not be mixed with separated stone. The clean rice was collected at the lower part of the inclined sieve.

\subsection{Performance evaluation of modified rice destoner}

Performance of the machine was evaluated to determine the ability of the material to flow freely through the sieves and the cleaning efficiencies of the machine with respect to impurity separation from rice.

\subsubsection{Chaff Cleaning efficiency}

This is the amount of chaff discharged through appropriate ducts to the total amount of the introduced into the hopper, expressed in percentage. It was computed using Eq. (11).

$C_{\text {eff }}=\frac{M_{c}}{M_{t}} \times 100$ 
where $\mathrm{C}_{\mathrm{eff}}=$ chaff cleaning efficiency $(\%), \mathrm{M}_{\mathrm{c}}=$ mass of chaff discharged through the appropriate chute $(\mathrm{kg}), \mathrm{M}_{\mathrm{t}}=$ total mass of chaff introduced into the grain $(\mathrm{kg})$.

\subsubsection{Stone Separation Efficiency}

This is the mass of stone removed to total mass of stone introduced into the rice. It was computed using the expression in Eq. (12).

$S_{\text {eff }}=\frac{M_{x}}{M_{p}} \times 100$

where, $S_{\text {eff }}=$ stone separation efficiency; $M_{\mathrm{s}}=$ mass of discharged rice in stone tank, $M_{p}=$ total mass of introduced into the hopper.

\subsubsection{Free Flow of Material through the Hopper Efficiency}

This is defined as the percentage of rice material introduced into the hopper and collected from the flow ducts when the machine is not at work. It was computed using Eq. (13).

$M_{e}=\frac{M_{1}}{M_{2}} \times 100$

where, $\mathrm{M}_{\mathrm{e}}=$ material flow efficiency $(\%) ; \mathrm{M}_{2}=$ mass of material introduced into the hopper $(\mathrm{kg}), \mathrm{M}_{1}=$ mass of material collected at the flow channel $(\mathrm{kg})$.

\section{Results and Discussion}

Results of performance evaluation of the modified rice destoner is shown in Table 1. It can be seen that the modified rice destoner has the design capacity of $1,800 \mathrm{~kg} / \mathrm{h}$. This may be as a result of the larger space on the two flat sides of its fan housing (casing) to draw sufficient air for better efficiency of the fan. The top of its grain channel was made open to allow for free agitating of the grains. Metal arm was introduced to help move the reciprocating panel in order to make for the sieving action of the destoner. The lower sieve efficiency of the machine was higher than efficiency of upper sieve and this may be due to the presence of more broken rice grains at the lower end. With the introduction of Lshaped metal arm, it was observed that the destoner was able to give a destoning efficiency of $40.8 \%$ higher than that of the existing machine. However, in contrast to this, Ogunlowo and Adesuyi [6], Simonyan et al. [11], Adejuyigbe and Bolaji [10] and Agidi et al. [13] reported higher destoning efficiency with lower machine capacity of rice destoner in their respective designs. It may be noted that this difference in efficiencies might be due to the differences in angle of inclination and the diameter of feed regulator opening of the machines. The present design presents an excellent machine capacity of $1800 \mathrm{~kg} / \mathrm{h}$ compared to that reported by Olugboji and Yisa [19] and Adejuyigbe and Bolaji [10]. Thus, clearly one can see that the modified machine will be able to handle more tonnes of rice per hour than most machines reported.
Table 1. Performance of the modified rice destoner

\begin{tabular}{llrl}
\hline s/n & Performance indices & Value & unit \\
\hline 1 & Machine capacity & 1.80 & $\mathrm{~kg} / \mathrm{h}$ \\
2 & Material flow efficiency: & & \\
& lower sieve & 97.0 & $\%$ \\
& upper sieve & 94.0 & $\%$ \\
3 & Cleaning efficiency: & & \\
& Chaffs & 85.0 & $\%$ \\
& Stones & 40.8 & $\%$ \\
\hline
\end{tabular}

\section{Conclusion}

An existing rice de-stoning machine was tested, modified and its performance was evaluated. The performance evaluation carried out on the machine after modification showed that the chaff cleaning, stone separation and material flow efficiencies through lower and upper sieves were relatively higher than the existing rice destoner. Also, the modified machine has an impressive material flow efficiency through the lower and upper sieves. This work also revealed that the design capacity of the modified machine was found to be $1.80 \mathrm{~kg} / \mathrm{h}$ which was higher than $0.86 \mathrm{~kg} / \mathrm{h}$ obtained from the previous machine. The machine was able to improve the quality of rice by de-chaffing and separation of broken rice particles.

\section{Acknowledgements}

Authors thank Engr. Oyewale babatunde Joseph for assisting in preliminary investigation of rice destoning machine as reported by Nwoba [14].

\section{References}

[1] O. Erenstein, F. Lançon, S.O. Akande, S.O. Titilola, G. Akpokodje, and O.O. Ogundele, "Rice production systems in Nigeria: A survey', WARDA, Abidjan, Cote d'Ivoire, 2003.

[2] E. A. Echiego, "Essential Consideration in the Grading and Packaging of Nigerian Rice for Export', Paper presented by Hon. Commissioner for Ministry of Agriculture and Natural resources Abakaliki, Ebonyi state, at the south - East Regional Conference of the Nigerian Institute of Agricultural Engineers, held at Abakaliki, Ebonyi State, 16th - 18th of September, 2009.

[3] J. O. Saka, and B. O. Lawal, "Determinants of adoption and productivity of improved rice varieties in south western Nigeria', African Journal of Biotechnology. Vol. 8 (19), pp. 4923 - 4932, 2009.

[4] F.A.O, "Farming systems and poverty: improving farmers' livelihoods in a change world', Rome: Food and agricultural organization, 2001.

[5] E. D. Imolehin, and A. C. Wada, "Meeting the Rice Production and Consumption demand of Nigeria with improved Technologies', National Cereal Research 
Institute, Badeggi, PMB 8,Niger State, Nigeria.pp1-11, 2000.

[6] A. S. Ogunlowo, and A. S. Adesuyi, "A Low cost rice cleaning/destoning machine", Published by European Centre for Research Training and Development UK, Vol.2, No.2, pp. 33-43, 2014.

[7] A. Fadeyibi, Z.D. Osunde, M.S. Ussaini, P.A. Idah, and A.A. Balami, "Evaluating Monolayer Moisture Content of Rubber Seed using BET and GAB Sorption Equations", International Journal of Farming and Allied Sciences, vol. 1(3), pp. 72-76. 2012.

[8] A. A. Okunola, J. C. Igbeka, A. G. Arisoyin, "Development and evaluation of a cereal Cleaner", Journal of Multidisciplinary Engineering Science and Technology, vol 2 issue 6, pp. 14-19, 2015.

[9] S.M. Henderson, and R.L. Perry, "Agricultural Process Engineering', 3rd Edition. The avi Publishing Company, Incorporated, West - port, Connecticut. Pp 170 - 189, 1976.

[10] S.B. Adejuyigbe, and B.O. Bolaji, "Development and Performance Evaluation of A Rice Destoning Machine Using Vibrating Sieves', Journal of Natural Science, Engineering and Technology Agricultural Mechanization in Asia, Africa and Latin America, 30 (1): $20-24,2012$.

[11] K. S. Simonyan, I. S. Emordi, and J. C. Adama, "Development of A Locally Designed Rice Destoning Machine', Journal of Agricultural Engineering and Technology (JAET), vol. 18 (1), 2010.

[12]I.K. Adegun, S.A. Adepoju, and J.A. Aweda, "A mini "Rice Processing Machine for Nigerian Farmers", Journal of Agricultural Technology, 8 (4): 1207-1216, 2012.
[13] G. Agidi, B. Ndagi, A. M. Kuku, and L. Abdullahi, "Development and Testing of A Rice Destoning Machine', International Journal Engineering. Resources \& Science \& Technology, 2015. ISSN 2319-5991. www.ijerst.com 4(3), 2015.

[14] Nwoba, "Design and Fabrication of Rice destoner" B.Eng. final year project in Agric. Engineering Department, Federal University of Technology, Minna of bean dehuller. Journal of Science and Technology, KNUST, Kumasi, Ghana, 25(1): 125-132, 1992.

[15] S.M.A. Razavi, S. Yaganehzad, and A. Sadeghi, "Moisture Dependant Physical Properties of Canola Seeds", Journal of Agricultural Science and Technology, vol. 11, 309-322, 2009.

[16]A. Tabatabee-far, "Moisture Dependant Physical Properties of Wheat', International Agrophysics, 17: 207-211, 2003.

[17] R. S. Khurmi, and J. K. Gupta, "A textbook of machine design', Eurasia Publishing House (PVC) Ltd. Ram Nagar, New Delhi. pp 509-543, 686-960, 2007.

[18] G. Nwithiga, L. Moriasi, "Study of Yield Characteristics during Mechanical Oil Extraction of Predicated and Ground Soybean', Journal of Applied Science Research, 3(10): 1146-1152, 2007.

[19] O. A. Olugboji, and J. Y. Jiya, "Design and Fabrication of Rice Destoning Machine. Journal of Food Science and Technology", vol. 2 (1): pp. 1-5, 2014. 